\title{
Influence of thymoxamine on changes in pupil diameter and accommodation produced by homatropine and ephedrine
}

\author{
SUSAN SMALL AND J. H. STEWART-JONES \\ From the Department of Ophthalmic Optics and Visual Science, City University, London \\ AND \\ P. TURNER \\ From the Department of Clinical Pharmacology, St Bartholomew's Hospital, London
}

Thymoxamine is an $\alpha$ adrenoceptor blocking drug which has miotic actions when applied topically in the eye (Sneddon and Turner, I968; Turner, 1969). It has been recommended for reversal of the potent mydriatic effect of a combination of eucatropine and phenylephrine (Smith, 1971). Since several types of mydriatic agents are used clinically, a study has been carried out to investigate the miotic effect of thymoxamine after treatment with homatropine and ephedrine separately and in combination.

\section{Material and methods}

Twelve healthy students (six men, six women), aged 19-21 years, and with various eye colours volunteered for the investigation. Each was subjected at weekly intervals, in random order based on three Latin square designs, to four different treatments shown in Table I. Before instillation of any drug into the conjunctival sac, the pupil diameter was measured using a clear Perspex pupillometer in which holes of various sizes were drilled for direct comparison with the subject's pupil and which measured pupil diameter to the nearest $0.5 \mathrm{~mm}$. Uniocular amplitude of accommodation was recorded for both eyes using a Duane near-point rule, the other eye being occluded. The mydriatic agent or saline was then instilled into both eyes, and at $30 \mathrm{~min}$ thymoxamine 0.1 per cent was instilled into the right eye. Pupil size was recorded at $30 \mathrm{~min}$ after the start of the experiment just before instillation of thymoxamine and then at $15 \mathrm{~min}$ intervals until $90 \mathrm{~min}$. The amplitude of accommodation was recorded at 30,60 , and 90 min. Illumination was kept constant in the laboratory throughout the investigation.

\section{Results}

The mydriatic effects of the treatments used, their reversal by thymoxamine, and the changes in amplitude of accommodation are shown in the

Address for reprints: Professor P. Turner, Department of Clinical Pharmacology, St Bartholomew's Hospital, West Smithfield, London ECIA 7 BE
Figure. The statistical analyses of differences $\stackrel{\circ}{\supset}$ between the eyes in pupil diameter and amplitude $\vec{T}$ of accommodation at $90 \mathrm{~min}$ using a paired $\Phi$ Student's $t$ test are given in Table II.

After treatment with saline, thymoxamine produced the expected miosis in all subjects. It also
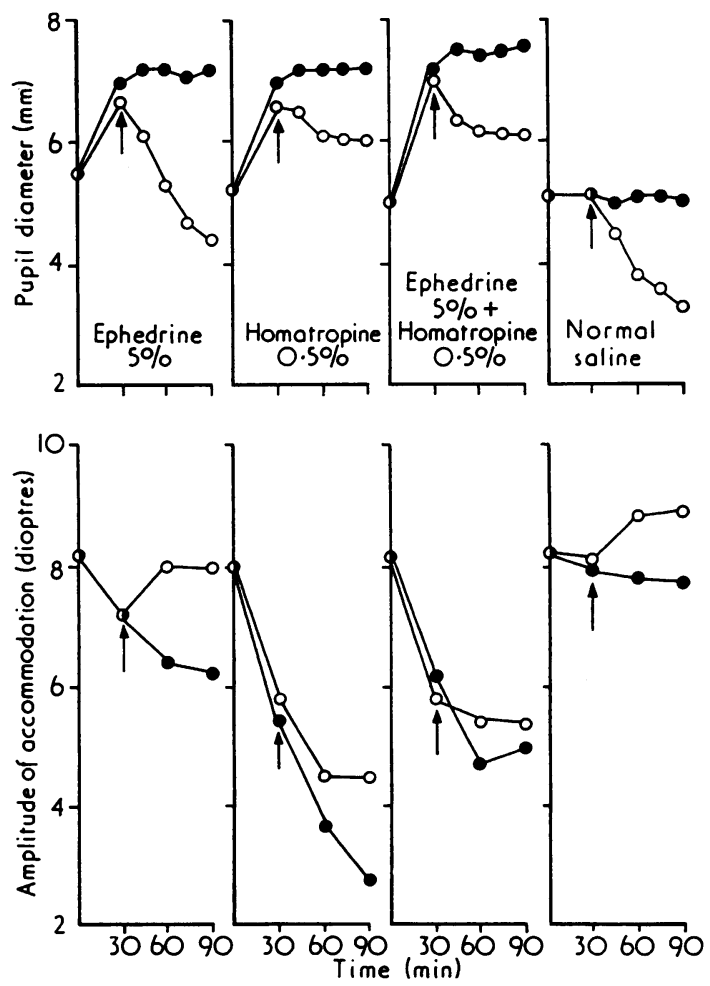

FIGURE Changes in pupil diameter and accommodation produced by normal saline, ephedrine, and homatropine alone and in combination, instilled into both eyes at zero time and observed over $90 \mathrm{~min}(\mathrm{O}-\mathrm{O})$ and their modification by thymoxamine (O-O) instilled into one eye at $30 \min (\uparrow)$, in 12 subjects 
produced a small but significant increase in amplitude of accommodation compared with the opposite untreated eye. The mydriasis induced by ephedrine was completely reversed by thymoxamine. A small but significant reduction in accommodation was found after ephedrine, and this was also reversed by thymoxamine. Thymoxamine failed to reverse completely at $90 \mathrm{~min}$ the mydriasis produced by homatropine, nor did it reverse completely the reduction in amplitude of accommodation produced by homatropine. Similar results were obtained with the combination of ephedrine and homatropine. The mydriasis produced by the combination was significantly greater $(P<0.01)$ than that produced by homatropine alone. All treatments were well tolerated. In particular, thymoxamine in the concentration of 0.1 per cent produced no irritation, giving less discomfort than ephedrine 5 per cent.

\section{Discussion}

These results confirm those of Smith (197I) that thymoxamine eye drops quickly reduce the mydria-

Table I Mydriatic regimens employed in both eyes of 12 volunteers 30 min before instillation of thymoxamine into the right eye

\begin{tabular}{ll}
\hline Regimen & $\begin{array}{l}\text { Drug instilled at zero time into right } \\
\text { and left eye }\end{array}$ \\
\cline { 1 - 1 } & $\begin{array}{l}\text { Ephedrine hydrochloride } 5.0 \text { per cent } \\
\mathrm{B}\end{array} \quad \begin{array}{l}\text { Homatropine hydrochloride } 0.5 \text { per cent } \\
\begin{array}{l}\text { Ephedrine hydrochloride } 5.0 \text { per cent } \\
\text { and homatropine hydrochloride } 0.5 \\
\text { per cent }\end{array} \\
\end{array} \quad$ Sodium chloride 0.9 per cent \\
\hline $\mathrm{D}$
\end{tabular}

sis produced by a combination of an anticholinergic drug with a sympathomimetic amine. The reversal is not complete, however, for the sympathetically mediated dilator pupillae component plays a smaller part in the mydriasis than reduction of the parasympathetically mediated sphincter pupillae component (Mapstone, 1970).

This is further demonstrated by the very small, although statistically significant, difference between the mydriasis produced by homatropine alone and that by its combination with ephedrine. This has important implications in other situations in which patients may be treated with drugs possessing anticholinergic properties. For example, Ghose, Dobree, Taylor, and Turner (1974) showed that the miotic effects of thymoxamine and of guanethidine are reduced in patients receiving amitriptyline, a tricyclic antidepressant drug, probably because of its anticholinergic activity. While it is possible that a higher concentration of thymoxamine such as 0.5 per cent would have produced a greater miosis in the present study, it causes marked irritation in many subjects, and cannot be recommended for routine use.

While it is generally reported that ephedrine does not cause cycloplegia, these results show that ephedrine 5 per cent produced a small but statistically significant reduction in accommodation, and so confirm the observations of Howard and Lee (1927) and Mitchell (1959) that ephedrine I-IO per cent produced a fall in accommodation of $0.25-2.50$ dioptres. The increase in accommodation produced by thymoxamine is consistent with these observations. It is probable that this is associated with the changes in pupil size produced by these agents, as Campbell (1957) showed that an increase in pupil diameter was accompanied by an increase in the hyperfocal distance. Such changes must be considered when accommodation studies are performed in patients with sympathetically mediated pupillary disorders.

Table II Influence of thymoxamine 0.1 per cent on the mydriasis and change in accommodation produced after 90 min by ephedrine, homatropine, and a mixture of ephedrine and homatropine in 12 subjects

\begin{tabular}{|c|c|c|c|c|c|c|c|c|c|c|}
\hline \multirow{2}{*}{ Treatment } & \multicolumn{5}{|c|}{ Mean pupil diameter ( $\mathrm{mm}$ ) } & \multicolumn{5}{|c|}{ Mean amplitude of accommodation (D) } \\
\hline & $\begin{array}{l}\text { No thy- } \\
\text { moxamine }\end{array}$ & $\begin{array}{l}\text { Thymoxa- } \\
\text { mine }\end{array}$ & $\begin{array}{l}S E \\
\text { diff. }\end{array}$ & $t$ & $P$ & $\begin{array}{l}\text { No thy- } \\
\text { moxamine }\end{array}$ & $\begin{array}{l}\text { Thymoxa- } \\
\text { mine }\end{array}$ & $\begin{array}{l}S E \\
\text { diff. }\end{array}$ & $t$ & $P$ \\
\hline $\begin{array}{l}\text { Saline } \\
\text { Ephedrine }\end{array}$ & $5 \cdot 1$ & $3 \cdot 5$ & 0.15 & $10 \cdot 7$ & $<0.001$ & $7 \cdot 9$ & $8 \cdot 9$ & 0.45 & $2 \cdot 29$ & $<0.05$ \\
\hline $\begin{array}{l}5 \text { per cent } \\
\text { Homatropine }\end{array}$ & $7 \cdot 2$ & $4 \cdot 4$ & 0.21 & $13 \cdot 3$ & $<0.001$ & $6 \cdot 4$ & $7 \cdot 9$ & 0.57 & $2 \cdot 72$ & $<0.02$ \\
\hline $\begin{array}{l}0.5 \text { per cent } \\
\text { Ephedrine }+\end{array}$ & $7 \cdot 3$ & $6 \cdot 0$ & 0.11 & I $1 \cdot 4$ & $<0.001$ & $2 \cdot 9$ & $4 \cdot 6$ & 0.42 & $4 \cdot 03$ & $<0.01$ \\
\hline Homatropine & $7 \cdot 7$ & $6 \cdot 2$ & 0.14 & 10.9 & $<0.001$ & $5 \cdot 2$ & $5 \cdot 9$ & 0.30 & $2 \cdot 20$ & $<0.05$ \\
\hline
\end{tabular}




\section{Summary}

Local instillation of thymoxamine eye drops $(0 \cdot 1$ per cent) completely reversed the mydriasis produced by ephedrine ( 5 per cent) but not that produced by ephedrine ( 5 per cent) together with homatropine $(0.5$ per cent). Small but significant changes in accommodation were found with ephedrine and with thymoxamine, as well as the larger expected changes with homatropine.

We thank the 12 students who participated as volunteers in this study, and William Warner \& Co Ltd for supplying thymoxamine.

\section{References}

CAMpbell, F. W. (1957) Optica Acta, 4, 157

GHOSE, K., DOBREE, C., TAYLOR, P., and TURNER, P. (1974) Brit. F. clin. Pharm., I, 5 I 6

HOWARD, H. J., and LEE, T. P. (1927) Proc. Soc. exp. Biol. (N.Y.), 24, 700

MAPSTONE, R. (1970) Brit. F. Ophthal., 54, 690

MITChelL, D. W. A. (1959) 'The Use of Drugs in Refraction', 2nd ed. British Optical Association, London SMITH, S. E. (197I) Lancet, 2, 837

SNEDDON, J. M., and TURNER, P. (1968) Clin. Pharmacol. Ther., 9, 45

TURNER, P. (1969) 'Clinical Aspects of Autonomic Pharmacology'. Heinemann, London 